\title{
Methods of Extraction of Micro- and Nanoparticles of Metal Compounds \\ from Fine Fractions of Rocks, Ores and Processing Products
}

\author{
A. Smetannikov ${ }^{(\bowtie)}$ and D. Onosov \\ PFIC UB RAS “GI UB RAS”, Perm, Russia \\ smetannikov@bk.ru
}

\begin{abstract}
The presented extraction methods are based on the features of the state of liquids in the capillary space in the form of a weak electrolyte. These methods make possible to extract micro- and nanoparticles adsorbed in matrix minerals from a suspension placed in the graphite substrate into a capillary solution. After the particle deposition in the substrate due to evaporative concentration the microprobe analysis is performed. The method is known as the capillary method of extracting micro and nanoparticles.

The described methods was used as a prototype for extracting micro- and nanoparticles from suspensions associated with the use of an external electric field. The field is created by connecting the electrodes to a graphite substrate and applied suspension with a direct current source using the voltage of $4 \div 6 \mathrm{~V}$. The micro- and nanoparticles adsorbed in matrix minerals are extracted into the capillary solution. The deposition of micro- and nanoparticles in a capillary solution is made by the method of evaporative concentration. The application of an external electric field intensify extraction of micro- and nanoparticles.
\end{abstract}

Keywords: Nanoparticles $\cdot$ Capillaries $\cdot$ Electrolyte $\cdot$ Graphite $\cdot$

Electric potential $\cdot$ Adsorption

\section{Introduction}

The following methods of extraction of minerals trace from rocks, ores and products of their processing are well known.

1. In heavy liquids with subsequent magnetic and electromagnetic separation of heavy fractions (Chueva 1950; Mitrofanov et al. 1974). The disadvantage of this method is the aggregation of nanoparticles with minerals with a particle size less than $0.045 \mathrm{~mm}$ and their absence in the heavy fraction.

2. Extraction of rhenium from ores of black shale formations (Oleynikova et al. 2012. The method for the extraction of micro- and nanoparticles of metal compounds is not calculated.

3. Extraction of nanoparticles from disperse systems (Zhabreev 1997) using the electric field created by electromagnets. The method does not provide for the extraction of all classes of metal compounds. 
4. Method of capillary extraction of nanoparticles (Smetannikov 2014). The material of fine fractions $(<0.25 \mathrm{~mm})$ mixing with a liquid forms of suspension, placed in the form of a hemisphere in a graphite substrate. The distance between minerals is comparable to their size and forms a capillary space. The liquid acquires structure, charge and becomes electrolyte (Deryagin et al. 1989). Nanoparticles adsorbed in matrix minerals are extracted into the capillary solution.

Due to the evaporation concentration, the nanoparticles migrate to the base of the hemisphere. After drying $(1 \div 1.5 \mathrm{~h})$, the hemisphere is removed, and the nanoparticles on the substrate are examined under a microprobe (Fig. 1). More than 50 minerals have been identified: intermetallic compounds and solid solutions of $\mathrm{Au}, \mathrm{Cu}, \mathrm{Ag}, \mathrm{Zn}$, $\mathrm{Pb}, \mathrm{Ni}, \mathrm{Sn}, \mathrm{Cu}, \mathrm{Fe}, \mathrm{Cr}$, Ti zircon, Sn minerals, monazite, which are trace substances in the water-insoluble salt residues of the Verkhnekamsk deposit (Smetannikov and Filippov 2010).

The disadvantage of this method is incomplete extraction of nanoparticles. This method served as a prototype for developing method for extracting particles using the methods of intensifying the natural properties of capillary systems by an external electric field.

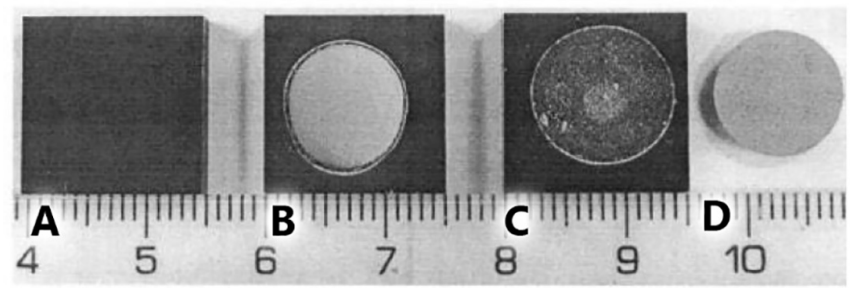

Fig. 1. A - clean graphite plate; B - a plate with a dried hemisphere of the investigated suspension; C- a plate with a hemisphere removed; D - Dried hemisphere (flat side up)

\section{Methods and Approaches}

The suspension is prepared from the material of fine fractions using distilled water and adding salt. The suspension is applied to a graphite plate, forming the hemisphere. An electrode with a "plus" sign (forming an anodic part of the system with a graphite plate) is connected to the underside of the plate. The second electrode is immersed in the suspension (without touching the graphite substrate) with a minus sign serves as a cathode. Then there is inclusion of the direct current voltage of $4 \div 6 \mathrm{~V}$. Further there is an electrolytic extraction of nanoparticles and deposition on the substrate. The dried hemisphere is removed and the sediment is analyzed.

There were conducted three experiences. The first is capillary sedimentation. The second experiment is anodic deposition, with a graphite plate serves as an anode. The third experiment is with pole reversal, when the upper (positive) electrode serves as the anode and the graphite plate as the cathode. Figure 2 posted three photos of deposition traces in three experiments. 
In the first experiment, there were matrix minerals practically absent, the number of nanoparticles is minimal (Fig. 2A). In the second experiment, the number of matrix minerals and nanoparticles is 1-2 orders of magnitude higher than in the first experiment (Fig. 2B). In the third experiment, an intermediate result (Fig. 2C). The maximum of nanoparticles is fixed in the second experiment. Here, the deposition process is enhanced by heating the graphite plate.

Experiments have shown the natural properties of water in a capillary space change created by a constant current source under the influence of an electric field. Capillary solution acquires the properties of an electrolyte. The salt concentration in the suspension is $0.5-1 \%$.

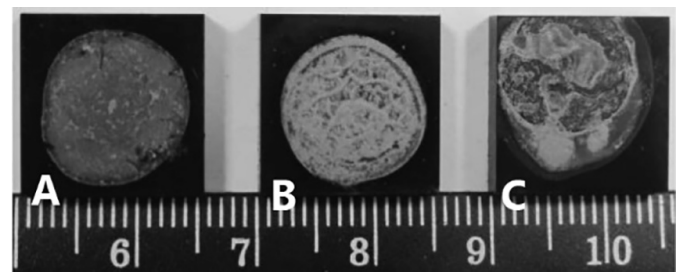

Fig. 2. A - sediment after capillary leaching; B - sediment after electrolytic anodic leaching; C - sediment after cathodic leaching

\section{Results and Discussion}

Extraction of micro- and nanoparticles from insoluble residues of salts, rocks, ores and products of their processing is provided by creating an electric field. The field creates the extracting properties of the electrolyte in suspension from the material of fine fractions and salt solution.

This factor ensures maximum extraction of micro- and nanoparticles and their fixation on a graphite substrate for subsequent analysis is by the microprobe method. Moreover, it is possible to solve the direct problem - the extraction of micro- and nanoparticles from insoluble residues of salts, ores and technogenic products, as well as the inverse problem - "cleansing" any small fraction of the material from impurities of minerals and metal particles.

While using the capillary-electrolytic method of extracting micro- and nanoparticles, the leaching effect (extraction) is achieved by 1-2 orders of magnitude higher than the results of the application of the prototype. The main goal is to obtain information of the form of finding elements-microimpurities. This result has been achieved. Researches are confirmed by the patent (Smetannikov and Onosov 2018).

\section{Conclusions}

1. The method relates to the methods for extracting micro- and nanoparticles of metal compounds from various media under the influence of direct electric current in a suspension of the material under study, water and salt, placed in a graphite substrate. 
2. The new method is different from the prototype by the use of an external electric field, the intensity of extraction of nanoparticles and the completeness of extraction.

\section{References}

Chueva MN (1950) Mineralogical analysis of schlich and ore concentrates. Gosgeolizdat, Moscow, p 179

Deryagin BV, Churaev NV, Ovcharenko FD et al (1989) Water in disperse systems. Chemistry, $288 \mathrm{p}$

Mitrofanov SI et al (1974) Mineral studies for enrichment. Nedra, Moscow, p 352

Oleynikova GA et al (2012) A nanotechnological method for extracting rhenium from rocks and ores of black shale formations. Patent No. 245237 RU, St. Petersburg State University (RU), Claims 12 June 2010. Publ. 10 July 2012, Bul. No. 19

Smetannikov AF (2014) Capillary method of extracting micro- and nanoparticles of minerals from fine fractions for subsequent microprobe analysis. Yushkinsky readings 2014, Materials of the mineralogical seminar with international participation, Syktyvkar, pp 177, 178

Smetannikov AF, Filippov VN (2010) Some features of the mineral composition of salt rocks and products of their processing (for example, Verkhnekamsk salt deposit). Scientific readings of the memory of P.N. Chirvinsky: Sat. articles, Perm, Issue 13, pp 99-113

Smetannikov AF, Onosov DV (2018) Capillary electrolytic method of extracting micro- and nanoparticles of metal compounds from fine fractions of rocks, ores and industrial products. Patent №2659871, PFIC UB RAS (RU), Declared. 20 December 2016, Published 04 July 2018

Zhabreev VS (1997) Installation for the extraction of substances and particles from suspensions and solutions. Patent 32098193 (RU), Chelyabinsk State Technical University, Appl. 26 July 1995, Publ. 10 December 1997

Open Access This chapter is licensed under the terms of the Creative Commons Attribution 4.0 International License (http://creativecommons.org/licenses/by/4.0/), which permits use, sharing, adaptation, distribution and reproduction in any medium or format, as long as you give appropriate credit to the original author(s) and the source, provide a link to the Creative Commons license and indicate if changes were made.

The images or other third party material in this chapter are included in the chapter's Creative Commons license, unless indicated otherwise in a credit line to the material. If material is not included in the chapter's Creative Commons license and your intended use is not permitted by statutory regulation or exceeds the permitted use, you will need to obtain permission directly from the copyright holder.

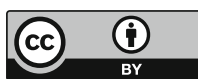

